\title{
Skeletal dysmorphology in fetus following colloidal silver ingestion in pregnant Swiss albino mice
}

\begin{abstract}
Among all nanoparticles Silver nanoparticle is important because of its antifungal \& antimicrobial activity and also known to be anti-inflammatory and wound healer. Silver nanoparticle is a strong bactericidal agent as it cleaves silver ion of atomic valency one inside the bacterial cell. Silver nanoparticle in moderate manner causes neurotoxicity, skeletal dysmorphogenesis and embryo teratogenicity in in-vitro position of model mouse. 20 to $1908 \mathrm{~nm}$ size silver nanoparticles in colloidal solution was given in dose $(5,10$, $15,20 \mathrm{mg} / \mathrm{kg}$ b.w.) respectively to randomly chosen mother mice from the colony by oral gavages from 7th to 12th day of gestational age. The control group mother received normal saline. Fetuses were collected on day 18th of gestation. Alizarin staining was done to evaluate the skeletal dysmorphology. The common skeletal dysmorphology seen were unossification of sternum, frontal bone, parietal bone, temporal bone, mandible, maxilla, vertebral column, scapulae and ribs along with those cleft, scoliosis, spina bifida and hypoplasia was also seen.
\end{abstract}

Keywords: eviscerate, vertebral column deformity, anencephaly, closed type neural tube deformity, silver nanoparticle colloidal solution
Volume 4 Issue 2 - 2017

\author{
Jyoti Prakash Pani,' Royana Singh ${ }^{2}$ \\ 'Department of Anatomy, Sir Nandkumar Y Tasgaonkar Institute \\ of Medical Science and Research, India \\ ${ }^{2}$ Department of Anatomy, Banaras Hindu University, India
}

Correspondence: Royana Singh, Professor Department of Anatomy, Institute of Medical Sciences, Banaras Hindu University,Varanasi, Uttar Pradesh, India, Tel 9450545650, Fax 05422367568, Email singhroyana@rediffmail.com

Received: April 30, 2017 | Published: August 21, 2017

\section{Introduction}

The present industrial sector related to textile industry, medicine product industry, house hold industry have enormously spread the use of Silver nanoparticle. Varieties of teratogenic effects are executed due to silver nanoparticle among which one of the important is skeletal dysmorphology. The discovery of the new facts can be compared with the quotes from some studies ${ }^{1}$ reveals that there is some chemical agents and drugs can induce teratogenic effects on the contrary silver nanoparticle induces skeletal dysmorphology in higher dose oral gavages schedules. On the due course of development it evokes major congenital abnormalities of various systems of offspring's which is seen in developed countries like USA and Canada about 3 to $5 \%$ and in developing countries like India, Mauritania etc about 20 to $25 \%{ }^{2}$ The devastating effects of drug, manually made colloidal solution, viruses and other facts related to our ecology is responsible for $1 \%$ of congenital defects of known and unknown etiology. ${ }^{3}$ Old studies on invitro risk assessment reported silver nanoparticle translocation which causes decreased cell viability, cell membrane damage and other histological hazardous effects. Several other studies also indicated silver nanoparticle to be most toxic among all metal nanoparticles. ${ }^{4-6}$ A toxicity of minimum level is denoted when HL-60 cell grown on metal silver plate. Some researchers did accumulation of nano silver on cells experiment ${ }^{7-11}$ and denoted that maximum accumulation can be cytotoxic in rat liver cell and Mammalian germ line stem cells. ${ }^{12}$

The current study also enlights the present world about effect of silver nanoparticle on skeletal system. It was undertaken to evaluate $\&$ assess the teratogenic effects: skeletal dysmorphology of Swiss albino mice fetuses through repeated oral gavages.

\section{Material and methods}

The present study was carried out, with rules and regulation for care and use of laboratory animals of the animal house and the respective experiment were approved by Central Animal Ethical Committee.
25 female Swiss albino mice with an average age 45 days and 25 to $35 \mathrm{gm}$ weight were chosen randomly from Animal house, from different breeding colonies. These female non pregnant adults were intentionally copulated by male mouse of same variety with an aim for procuring 10 pups of further generation. In the plastic polycarbonate cage with stainless steel toppings single strong and stout heterozygous male were placed with single female in an atmosphere continuously maintained at $20-25^{\circ} \mathrm{C}$ and $55 \pm 5 \%$ humidity, $12 \mathrm{hrs} \mathrm{subsequently} \mathrm{light}$ and dark cycle. The female mice were examined for vaginal cross plug and presence of well visualize plug were marked as ascertained pregnancy and assigned day zero of gestational. On day 7, 8 and 9 of gestation plugged females were chequed for pregnancy by abdominal palpation.

\section{Characterization of AgNps}

Silver nanoparticles from research purchasing sources were evaluated for their primary size by TEM and for their agglomeration in cell medium by photon cross correlation spectroscopy (PCCS) and ultraviolet-visible (UV-Vis) spectroscopy, Dynamic light Scattering and Zeta potential. Representative TEM pictures of the AgNps were showed. The TEM images of the PVP coated AgNps dispersed and suspended in $1.5 \mathrm{M} \mathrm{NaCl}$ confirmed the primary particle size stated by the manufacturers. The uncoated silver nanoparticles found heterogeneous distribution within the range of 50 to $100 \mathrm{~nm}$, most of them being around $71 \mathrm{~nm}$.

In the case of suspended powder AgNps, TEM images showed that in an aqueous environment the silver nanoparticles clumping and form large aggregates, many of which are larger than $50 \mathrm{~nm}$. This result is in consistent with the results of hydrodynamic size distribution which was obtained from the dynamic light scattering method (zeta sizer). EDX analyses were confirmed that only elemental silver was presented in both colloidal and dry powdered AgNps. According to the ICP-AES results, the concentrations of Ag ions in the acid digested stocks of colloidal and suspended powder AgNps were 1908.1 and 
447.2mgl-1 respectively. Also results of the XRD pattern confirms the crystallinity of powdered type AgNps and presence of elemental crystalline silver, also other phases, except metallic silver, were not present in the sample. In addition the XRF results showed that purity of powdered type AgNps was $97.86 \%$.

\section{Exposure of AgNps colloidal solution through repeated oral gavages}

Pregnant mice were administered double with normal saline (Sham control) as vehicle and in a dose of $5,10,15,20 \mathrm{mg} / \mathrm{kg}$ b.w. were given through repeated oral gavages, from 7 to 12 gestational day with the help of a blunt tip curved shaft feeding needle and van attached. Sham control animals are included in experiment with treated animals and untreated animals.

\section{Dissection and evisceration}

On GD 18, right and left horns of uterus of pregnant mother were exteriorized following ventral laparotomy under deep ether/chloroform anesthesia and 250 fresh collected dams through dissection were washed with tap water on Petri dish to remove blood and amniotic fluid and dried by filter paper and dehydrated in $95 \%$ alcohol for $48 \mathrm{hrs}$ at last exposed to $1 \% \mathrm{KOH}$ for consistence evisceration and Alizarin staining protocol for proper visualization of bones either normal or abnormal. ${ }^{13}$

Method (Assessment of skeletal dysmorphology by the technique of evisceration and Alizarin staining)-:

Skeletal dysmorphology study was done by the technique of evisceration and Alizarin staining. All specimens (50 pups) from each group were dehydrated in $95 \%$ of alcohol ( rectified spirit) for 48 hours and then removed and washed by running tap water and then eviscerated by $1 \% \mathrm{KOH}$ solution (KOH $1 \mathrm{gm}+100 \mathrm{ml}$ d.w.). After doing ventral laparotomy vital organs are removed. The specimens were dipped thoroughly in plenty of $1 \%$ potassium hydroxide $(\mathrm{KOH})$ solution for at least 2 to 4 days until the flesh, tendon, muscles and viscera's were transparent \& clear and disband followed by crystal clear visibility of the bones and cartilages. Every day solution was changed when it become discolored and wastes.

The crystal clear bone and cartilage visible specimen were then placed in same $1 \% \mathrm{KOH}$ and then 6 to 8 drops of $1 \%$ Alizarin stain was added to color it deep purplish red. The solution was gently shaked a few times per hour. Then the same procedure was continued for another 2-3days in order to give deep purplish red color to bone and cartilages. For removal of any over staining and smoothening of the samples, the same are then passed through $40 \%, 80 \%(40 \mathrm{ml}$ glycerol $+60 \mathrm{ml}$ distilled water, $80 \mathrm{ml}$ glycerol $+20 \mathrm{ml}$ distilled water) and 1 to 2 crystal thymol added for long term preservation finally maintained in $100 \%$ glycerol, served for photograph \& powerful hand lens observation.
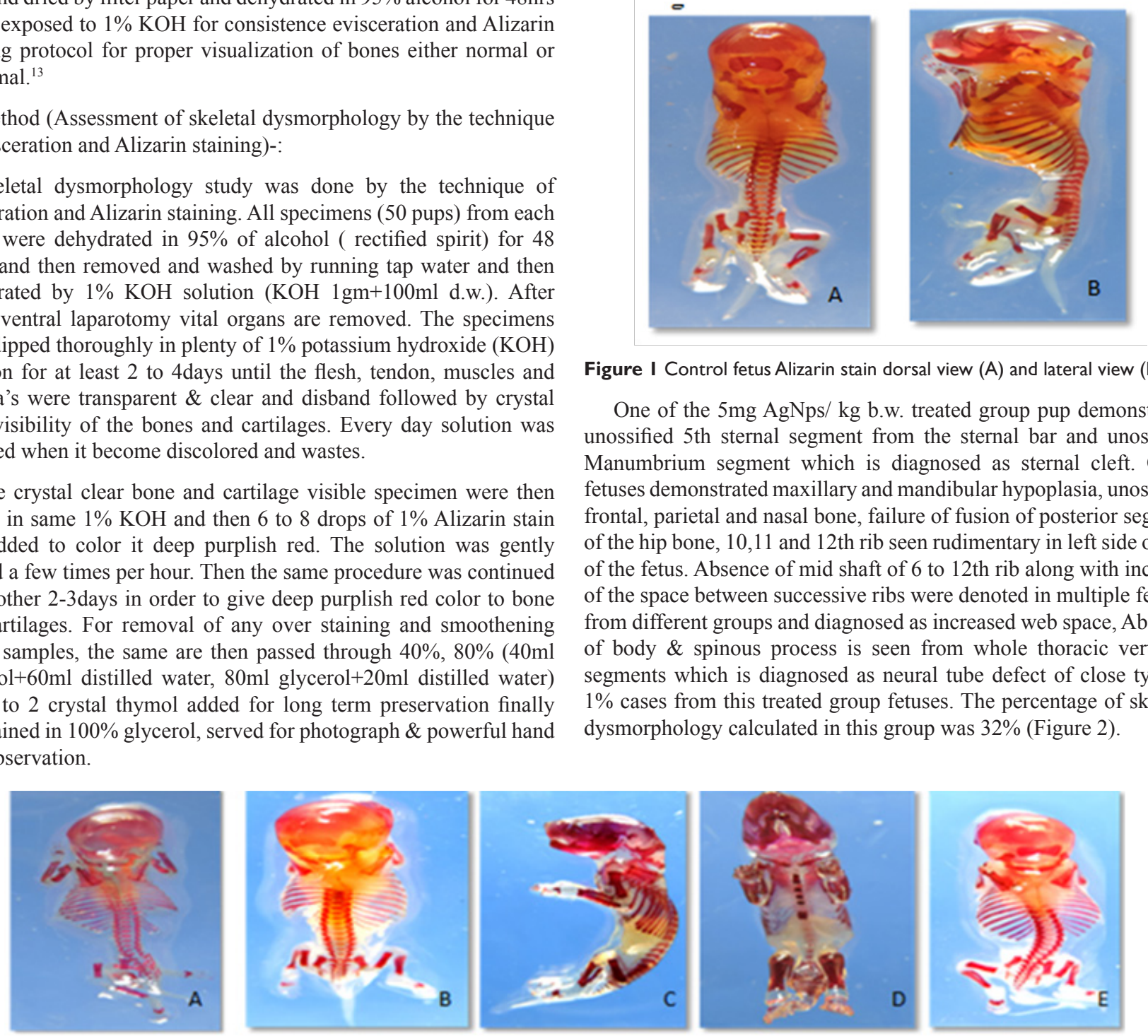

Figure I Control fetus Alizarin stain dorsal view (A) and lateral view (B).

One of the $5 \mathrm{mg} \mathrm{AgNps} / \mathrm{kg}$ b.w. treated group pup demonstrated unossified 5th sternal segment from the sternal bar and unossified Manumbrium segment which is diagnosed as sternal cleft. Other fetuses demonstrated maxillary and mandibular hypoplasia, unossified frontal, parietal and nasal bone, failure of fusion of posterior segment of the hip bone, 10,11 and 12th rib seen rudimentary in left side of one of the fetus. Absence of mid shaft of 6 to 12th rib along with increase of the space between successive ribs were denoted in multiple fetuses from different groups and diagnosed as increased web space, Absence of body \& spinous process is seen from whole thoracic vertebral segments which is diagnosed as neural tube defect of close type in $1 \%$ cases from this treated group fetuses. The percentage of skeletal dysmorphology calculated in this group was $32 \%$ (Figure 2).

Figure $25 \mathrm{mg} \mathrm{AgNps}$ treated group fetus Alizarin stain dorsal view (A) and (B), lateral view (C) ventral view (D) and dorsal view(E) 
Table I Various skeletal dysmorphology seen among the fetuses of 20, I5, I0,5mg/kg b.w.AgNps treated groups

\begin{tabular}{|c|c|c|c|c|}
\hline \multirow{2}{*}{ Groups } & \multirow{2}{*}{$\begin{array}{l}\text { Number of } \\
\text { pregnant mice } \\
\text { used per group }\end{array}$} & \multicolumn{3}{|c|}{ No. of fetuses with skeletal dysmorphology } \\
\hline & & $\begin{array}{l}\text { Pups } \\
\text { examined }\end{array}$ & Pups affected & Various skeletal dysmorphology met \\
\hline $\begin{array}{l}20 \mathrm{mg} \mathrm{AgNPs/} \\
\mathrm{kg} \text { b.w. treated } \\
\text { group }\end{array}$ & 5 & 50 & $38(76 \%)$ & $\begin{array}{l}\text { Scoliosis of lumbar region, unossified occipital bone, unossified maxilla, } \\
\text { frontal, parietal, occipital, scapulae and hip bone, increased space of Ist } \\
\text { to 5th, 7th and 8th rib in one \& } 10 \text { th, I I th and I } 2 \text { th ribs with incomplete } \\
\text { cartilages, big fibrosis of } 2 \text { nd to } 6 \text { th segment of sternum, cleft ankle joint, } \\
\text { cleft symphisis pubis, absence of spinous process, wavy ribs, mandibular } \\
\text { hypoplasia \& hypo plastic vertebrae. }\end{array}$ \\
\hline $\begin{array}{l}\text { I5mg AgNPs/ } \\
\text { kg b.w. treated } \\
\text { group }\end{array}$ & 5 & 50 & $30(60 \%)$ & $\begin{array}{l}\text { Absence of cervical vertebrae, absence of I } 2 \text { th rib, undeveloped spinous, } \\
\text { metatarsal cleft, unossified spinous process of all thoracic vertebrae, } \\
\text { unossified scapulae \& hip bone and absence of proximal segment, temporal } \\
\text { bone on lateral view, scoliosis of LI-L5 (F4), absence of cartilage of 6-I } 2 \\
\text { ribs. }\end{array}$ \\
\hline $\begin{array}{l}\text { I0mg AgNPs/ } \\
\text { kg b.w. treated } \\
\text { group }\end{array}$ & 5 & 50 & $22(44 \%)$ & $\begin{array}{l}\text { Absence of lumbar and sacral vertebrae and hip bone, severe degeneration } \\
\text { of rib without cartilages, unossified \& undeveloped frontal, parietal and } \\
\text { hip bone, scoliosis, maxillary hypoplasia, disclosure of coronal and sagittal } \\
\text { sutures, undeveloped lower limb bone of both sides. }\end{array}$ \\
\hline $\begin{array}{l}5 \mathrm{mg} \mathrm{AgNPs} / \\
\mathrm{kg} \text { b.w. treated } \\
\text { group }\end{array}$ & 5 & 50 & $16(32 \%)$ & $\begin{array}{l}\text { Unossified 5th sternebrae segment from sternal bar, unossified } \\
\text { manumbrium, sterna cleft, maxillary and mandibular hypoplasia, unossified } \\
\text { frontal and parietal bone. }\end{array}$ \\
\hline
\end{tabular}

The 10mg AgNps treated group fetuses demonstrated skeletal dysmorphology in the form of absence of lumbar and sacral vertebra, absence of hip bones, severely degenerated ribs without cartilages, frontal and parietal bone showed unossified and undeveloped, scoliosis is observed in thoracic and lumbar region in one of the fetus, absence of cervical vertebra is seen, maxillary hypoplasia, disclosure of sagittal and coronal sutures are also seen. Undeveloped lower limb bones are seen on both sides of one of the fetus. The percentage of skeletal dysmorphology calculated in this group was $44 \%$ (Figure 3 ).
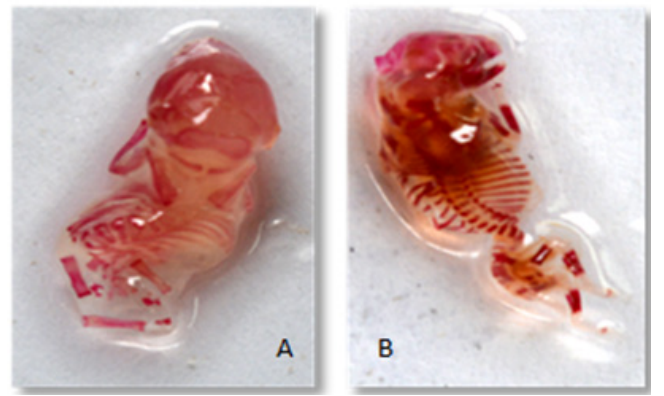

Figure 3 IOmg AgNps treated group fetus Alizarin stain dorsal view (A, B).

Among 15mg AgNps treated group 8 pups were observed absence of cervical vertebrae with absence of 12th rib and rest of the vertebrae were observed undeveloped spinous process, Metatarsal cleft is also seen on dorsal view of foot of one of the fetus, unossified hip bone on ventral view with absence of segment \& fibrosis is also seen, unossified temporal bone which is found fibrosed on lateral view of skull, absence of proximal segment of innominate bone, vertebral column anomaly was seen with rudimentary 6th and 9th rib and absence of 10th,11th and 12th is observed ribs in one of the fetus, unossified parietal bone was also seen, Anencephaly with scoliosis vertebrae was seen in L1-L5 in one of the fetus, unossified hip bone was seen, unossified scapulae of both side was seen on dorsal view of one of the fetus, Absence of cartilage was seen from 6th to 12th rib in one of the fetus. The percentage of skeletal dysmorphology calculated in this group was $60 \%$ (Figure 4 ).
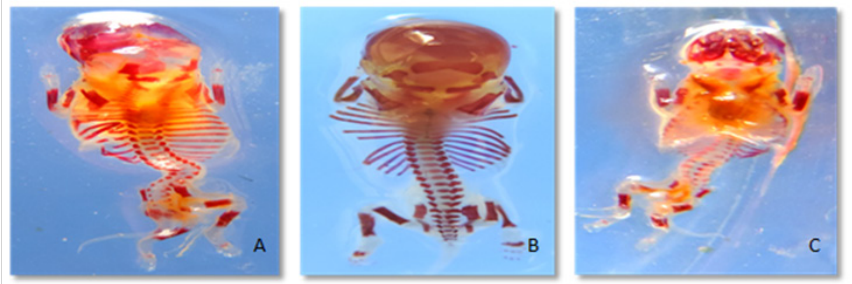

Figure 4 I5mg AgNps treated group fetus Alizarin stain dorsal view (A, B) and ventral view $(\mathrm{C})$

The $20 \mathrm{mg} / \mathrm{kg}$ b.w. AgNps treated group fetuses were presented highest percentage of skeletal dysmorphology (76\%). Scoliosis was seen in lumbar region in one of the fetus, one fetus demonstrated unossified occipital bone, unossified scapulae and hip bone, big fibrosis is observed in maxilla, frontal and parietal bones, same is also observed in second to sixth segment of sternum., cleft is observed in the ankle joint, increased space is observed between 1st and 2nd rib and 5th to 8th ribs of left side of one of the fetus, also cleft is observed in symphisis pubis joint of one of the fetus, unossified mandibular hypoplasia, absence of spinous process with wavy ribs is also observed, in one fetus we observed complete fusion of the 2nd to 8 th cervical vertebrae which is clearly differentiated from rest of the 1 st cervical vertebrae. We also observed mild scoliosis and unossified occipital and parietal bone and absence of scapulae on right side of one of the fetus, hypo plastic vertebrae is also seen (Figure 5). 


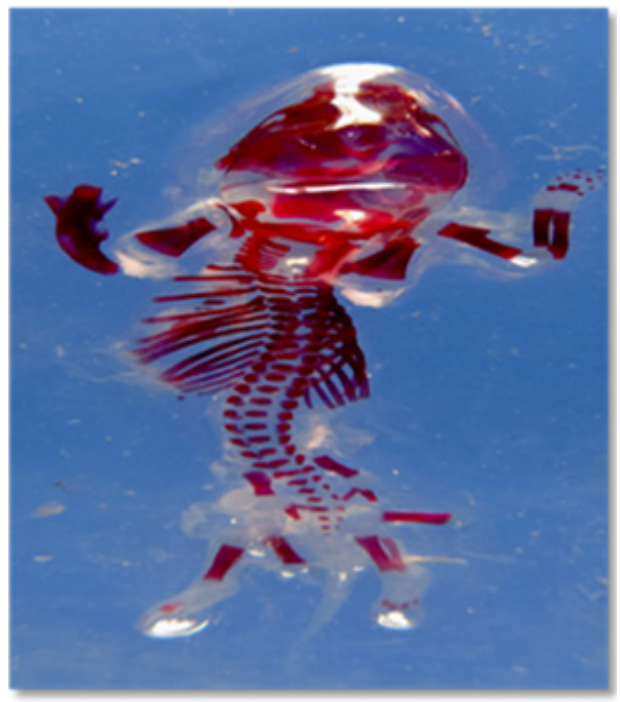

Figure 5 20mg AgNps treated group fetus Alizarin stain dorsal view.

\section{Discussion}

The present work was undertaken to study the effect of prenatal exposure of silver nanoparticle colloidal solution through repeated oral gavages on developing skeleton of mice embryos. The skeletal dysmorphology met in this study were in the form of unossified

Nanosilver shows antagonistic properties in lower dose that is antimicrobial and antiseptic properties (0.25-1mgAgNPs/kg b.w.) through topical application but surprisingly it shows teratogenic effects like skeletal dysmorphology in 5, 10, 15, 20mg AgNPs/ kg b.w. dose and toxic consequences in $0.5 \& 1 \mathrm{mg} / \mathrm{kg}$ b.w. dose through oral gavages as per studies by Benn et al. ${ }^{14}$ and Sawosz et al. ${ }^{15}$ reveals. This is definitely a big question for present research world who are really ignore about potential adverse effect. The question arise is why this potential adverse effect in higher dose but not in lower dose? Previously as per studies carried out by Stebunova et al. ${ }^{16} \&$ Kim et al. ${ }^{17}$ revealed sub acute and long term exposure of nanosilver produces swelling of lung parenchyma or in-vitro toxicity there is no long term effect in chronic translocation of nanosilver into other organs.

Though lot of researches has been carried out on vertebrate animal to demonstrate nanosilver teratogenicity still there is lack of relevant data available till today to show teratogenic effect of repeated oral gavages of synthesized silver compound during prenatal to natal period which cause drastic teratogenic effect like infertility, intrauterine growth retardation and other anomalies among which skeletal dysmorphology is predominant.

McCauley et al. ${ }^{18}$ did an experiment on pregnant cynomolgus monkeys in which he injected through vagina to uterus, $1 \%$ silver nitrate between 27 to 43 days of pre natal period and surprisingly it cause vaginal bleeding in early stage of ingestion and he also observed termination of pregnancy but as an antagonistic effect of silver compound he also observed another victim of the particular experiment redelivered healthy and normal offspring after getting pregnant. As per studies by Blumberg \& Carey $^{19}$ revealed \& also observed a systemic aberration called argyria (Blue baby syndrome) due to chronic, part by part ingestion of total $6.4 \mathrm{gm}$ silver nitrate within 6month in past. Rosen man et al. ${ }^{20}$ also did an experiment on old man worker by exposing silver dust on eye ball and respiratory tract \& he observed irritation of the former and he also observed temporal, frontal and occipital bones. As revealed by the groups $5 \mathrm{mg}, 10 \mathrm{mg}, 15 \mathrm{mg}, 20 \mathrm{mg} / \mathrm{kg}$ b.w. maxillary and mandibular hypoplasia, nasal bone hypoplasia, scoliosis, cleft, absence of segments of hip bone, failure of fusion of segments and large cases of increased intercostal spaces and other rib anomalies are encountered during the course of practical work conducted in this present study. Alizarin stain completely failed to reach up to tail region to stain the tail. There are plenty of data available among nanosilver toxicity from various manufactured products, this existing study indicated dysmorphology of skeletal system of vertebrate pups of Swiss albino mouse variety which is predominant among several type of teratogenicities executed till today (Figure 6).

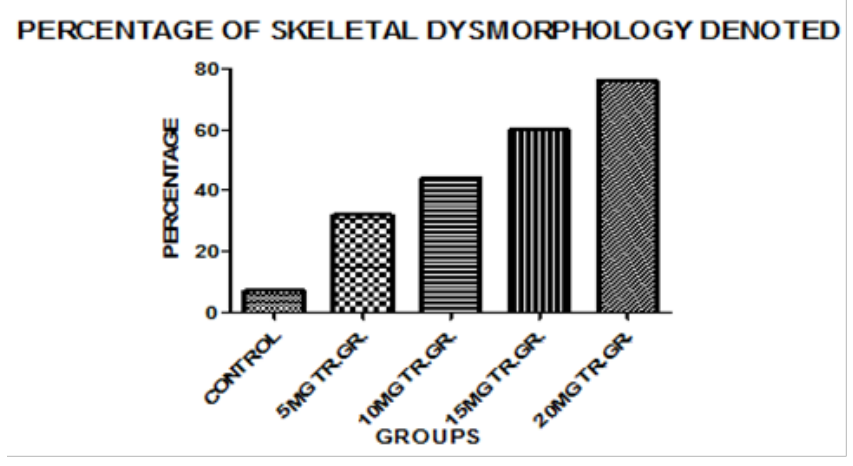

Figure 6 Percentage of skeletal dysmorphology denoted.

reduced capability of night vision in that worker. Moss et al. ${ }^{21}$ also did the same experiment and found to some extent same complication. The period of exposure divided was 1-10years. Another experiment was carried out by Moss et al. ${ }^{21}$ by exposing silver nitrate through inhalation in some worker in which he observed discoloration of the conjunctiva \& cornea. William ${ }^{22}$ also did the same and observed the same. As per recent studies by Chang et al. ${ }^{23}$ revealed by giving oral gavages of AgNo3 to an old man dermal distress, endocrine disorder, hyperlipidaemia \& hypertension with blue grey facial sign are observed. Tang \& $\mathrm{Xi}^{24}$ did an experiment on a very old man of about $80 y e a r s$ by applying self medication of silver where they observed myoclonic seizures in that old victim both of them also found to some extent same complication.

Stepien et al. ${ }^{25}$ \& Korani et al. ${ }^{26}$ study showed fatal consequences in higher dose Silver nitrate oral gavages administration along with liver, kidney and spleen toxicity histopathologically in medium dose administration, but still complete evidences are not available in plenty manner on teratogenicity of the silver compound on skeletal system.

The present work was undertaken to study the effect of prenatal exposure of silver nano particle colloidal solution through repeated oral gavages on developing skeleton of mice embryos. We found delayed ossification of occipital bone which was also reported as per studies by Chernoff. ${ }^{27}$ The skeletal dysmorphology observed were in the form of unossified temporal, frontal and occipital bones. Maxillary and mandibular hypoplasia, nasal bone hypoplasia, scoliosis, cleft , absence of segments of hip bone, failure of fusion of segments and large cases of increased intercostal spaces and other rib anomalies were also encountered during the course of the present study. Alizarin stain completely failed to reach up to tail region to stain the tail. There are plenty of data available among nano silver toxicity from various manufactured products, the present indicated dysmorphology of skeletal system of Swiss albino mice variety which is predominant among several types of teratogenicity executed till today. 
Studies by Stucky \& Berry ${ }^{28}$ revealed delayed skeletal growth our study also reported the same. Webster et al. ${ }^{29}$ and Rasmussen $\&$ Christensen $^{30}$ also reported maxillary hypoplasia our study also reported the same. In our study maxillary and mandibular hypoplasia exhibited as either a flat mid face or a narrow snout that can be compared with the typical human FAS features i.e. a flat mid face associated with maxillary and mandibular hypoplasia. It can also be termed as a small burst and tear nose or a vanished or completely absent philtrum with a long gap between the thinned upper lip as per studies revealed by Clarren et al. ${ }^{31}$ So keeping views and reporting of other scientists our study can be comparable with other study. In fact our study also showed different type of limb defects. As shown in Table 2 below.

Table 2 Category and disambiguation of limb defect induced by Silver nanoparticle colloidal solution in the Swiss albino mouse fetus

\begin{tabular}{|c|c|c|c|c|c|c|c|}
\hline $\begin{array}{l}\text { Type of } \\
\text { malformation, } \\
\text { n (\%) }\end{array}$ & $\begin{array}{l}\text { Control } \\
\text { group } \neq \\
(n=50)\end{array}$ & $\begin{array}{l}\text { Gestation d } \\
75-|0-| 5- \\
20(n=50) \mathrm{mg} / \\
\text { kg b.w. }\end{array}$ & $\begin{array}{l}\text { Gestation d } \\
85-|0-| 5- \\
20(n=50) \mathrm{mg} / \\
\text { kg b.w. }\end{array}$ & $\begin{array}{l}\text { Gestation d } \\
95-10-15- \\
20(\mathrm{n}=50) \mathrm{mg} / \\
\text { kg b.w. }\end{array}$ & $\begin{array}{l}\text { Gestation d } \\
\text { I0 5- I 0- I 5- } \\
20(\mathrm{n}=50) \mathrm{mg} / \\
\text { kg b.w. }\end{array}$ & $\begin{array}{l}\text { Gestation d } \\
\text { I I 5- | 0- I 5- } \\
20(\mathrm{n}=50) \mathrm{mg} / \\
\text { kg b.w. }\end{array}$ & $\begin{array}{l}\text { Gestation d } \\
\text { I } 25-10-15- \\
20(n=50) \mathrm{mg} / \\
\text { kg b.w. }\end{array}$ \\
\hline \multicolumn{8}{|c|}{ Forelimbs Micromelia } \\
\hline Short humerus & 0 & $0-0-0-0$ & $0-0-0-0$ & $0-0-0-0$ & $0-0-0-0$ & $0-0-0-0$ & $0-0-0-0$ \\
\hline $\begin{array}{l}\text { Short or bent } \\
\text { radius-ulna }\end{array}$ & 0 & $0-0-0-0$ & $0-0-0-0$ & $0-0-0-0$ & $0-0-0-0$ & $0-0-0-0$ & $0-0-0-0$ \\
\hline Apodia & 0 & $0-0-0-0$ & $0-0-0-0$ & $0-0-0-0$ & $0-0-0-0$ & $0-0-0-0$ & $0-0-0-0$ \\
\hline Adactyly & 0 & $0-0-0-0$ & $0-0-0-0$ & $0-0-0-0$ & $0-0-0-0$ & $0-0-0-0$ & $0-0-0-0$ \\
\hline Ectrodactyly & 0 & $0-0-0-0$ & $0-0-0-0$ & $0-0-0-0$ & $0-0-0-0$ & $0-0-0-0$ & $0-0-0-0$ \\
\hline Syndactyly & 0 & $0-0-0-0$ & $0-0-0-0$ & $0-0-0-0$ & $0-0-0-0$ & $0-0-0-0$ & $0-0-0-0$ \\
\hline \multicolumn{8}{|l|}{ Brachydactyly } \\
\hline $\begin{array}{l}\text { Absent phalanx } \\
\text { (ges) }\end{array}$ & 0 & $\begin{array}{l}I(2)-0-2(4)- \\
3(6)\end{array}$ & $\begin{array}{l}I(2)-0-2(4)- \\
3(6)\end{array}$ & $\begin{array}{l}I(2)-0-2(4)- \\
3(6)\end{array}$ & $\begin{array}{l}I(2)-0-2(4)- \\
3(6)\end{array}$ & $\begin{array}{l}I(2)-0-2(4)- \\
3(6)\end{array}$ & $\begin{array}{l}I(2)-0-2(4)- \\
3(6)\end{array}$ \\
\hline $\begin{array}{l}\text { Short or small } \\
\text { phalanx (ges) }\end{array}$ & 0 & $\begin{array}{l}0-3(6)-6(12)- \\
8(16)\end{array}$ & $\begin{array}{l}0-3(6)-6(12)- \\
8(16)\end{array}$ & $\begin{array}{l}0-3(6)-6(12)- \\
8(16)\end{array}$ & $\begin{array}{l}0-3(6)-6(12)- \\
8(16)\end{array}$ & $\begin{array}{l}0-3(6)-6(12)- \\
8(16)\end{array}$ & $\begin{array}{l}0-4(8)-6(12)- \\
9(18)\end{array}$ \\
\hline $\begin{array}{l}\text { Short or small } \\
\text { metacarpal }\end{array}$ & 0 & $0-0-I(2)-I(2)$ & $0-0-I(2)-I(2)$ & $0-0-I(2)-I(2)$ & $0-0-I(2)-I(2)$ & $0-0-I(2)-I(2)$ & $0-0-I(2)-I(2)$ \\
\hline $\begin{array}{l}\text { Short or small } \\
\text { carpal bone }\end{array}$ & 0 & $0-0-0-0$ & $0-0-0-0$ & $0-0-0-0$ & $0-0-0-0$ & $0-0-0-0$ & $0-0-0-I(2)$ \\
\hline $\begin{array}{l}\text { Fused phalanx } \\
\text { or phalanx and } \\
\text { metacarpal }\end{array}$ & 0 & $0-0-0-0$ & $0-0-0-0$ & $0-0-0-0$ & $0-0-0-0$ & $0-0-0-0$ & $0-0-0-0$ \\
\hline \multicolumn{8}{|c|}{ Hindlimbs micromelia } \\
\hline Short humerus & 0 & $0-0-0-0$ & $0-0-0-0$ & $0-0-0-0$ & $0-0-0-0$ & $0-0-0-0$ & $0-0-0-0$ \\
\hline $\begin{array}{l}\text { Short or bent } \\
\text { radius-ulna }\end{array}$ & 0 & $0-0-0-0$ & $0-0-0-0$ & $0-0-0-0$ & $0-0-0-0$ & $0-0-0-0$ & $0-0-0-0$ \\
\hline Apodia & 0 & $0-0-0-0$ & $0-0-0-0$ & $0-0-0-0$ & $0-0-0-0$ & $0-0-0-0$ & $0-0-0-0$ \\
\hline Adactyly & 0 & $0-0-0-0$ & $0-0-0-0$ & $0-0-0-0$ & $0-0-0-0$ & $0-0-0-0$ & $0-0-0-0$ \\
\hline Ectrodactyly & 0 & $0-0-0-0$ & $0-0-0-0$ & $0-0-0-0$ & $0-0-0-0$ & $0-0-0-0$ & $0-0-0-0$ \\
\hline Syndactyly & 0 & $0-0-I(2)-0$ & $0-0-I(2)-0$ & $0-0-I(2)-0$ & $0-0-I(2)-0$ & $0-0-I(2)-0$ & $0-0-I(2)-0$ \\
\hline \multicolumn{8}{|l|}{ Brachydactyly } \\
\hline $\begin{array}{l}\text { Absent phalanx } \\
\text { (ges) }\end{array}$ & 0 & $0-0-0-0$ & $0-0-0-0$ & $0-0-0-0$ & $0-0-0-0$ & $\begin{array}{l}\text { I(2)- 0-2(4)- } \\
4(8)\end{array}$ & $\begin{array}{l}\text { I(2)- 0-2(4)- } \\
4(8)\end{array}$ \\
\hline $\begin{array}{l}\text { Short or small } \\
\text { phalanx (ges) }\end{array}$ & 0 & $0-0-0-0$ & $0-0-0-0$ & $0-0-0-0$ & $0-0-I(2)-0$ & $\begin{array}{l}0-3(6)-6(12)- \\
9(18)\end{array}$ & $\begin{array}{l}0-4(8)-6(12)- \\
10(20)\end{array}$ \\
\hline $\begin{array}{l}\text { Short or small } \\
\text { metatarsal }\end{array}$ & 0 & $0-0-0-0$ & $0-0-0-0$ & $0-0-0-0$ & $0-0-I(2)-0$ & $0-0-I(2)-2(4)$ & $0-0-I(2)-2(4)$ \\
\hline $\begin{array}{l}\text { Short or small } \\
\text { tarsal bone }\end{array}$ & 0 & $0-0-0-0$ & $0-0-0-0$ & $0-0-0-0$ & $0-0-0-0$ & $0-0-0-0$ & $0-0-0-I(2)$ \\
\hline $\begin{array}{l}\text { Fused phalanx } \\
\text { or phalanx and } \\
\text { metatarsal }\end{array}$ & 0 & $0-0-0-0$ & $0-0-0-0$ & $0-0-0-0$ & $0-0-0-0$ & $0-0-0-0$ & $0-0-0-0$ \\
\hline
\end{tabular}

*,Administered through repeated oral gavages

$\neq$, Injected through oral gavages with vehicle on gestational day 7 
As a conclusion the present study showed skeletal dysmorphology effect through oral gavages of synthesized silver nanoparticle colloidal solution on pups of pregnant Swiss albino mice delivered by exteriorize of horns on 18th day of G.A. are the successive victims. The present study also indicates $5,10,15,20 \mathrm{mg} / \mathrm{k}$.g. b.w. repeated oral gavages from 7-12days of gestationaldays in pups of Swiss albino mice have definitely deleterious effect on skeletal system \& the intensity of teratogenicity like different grade of skeletal dysmorphology along with area of affection of tissue is also dose and size dependant.

\section{Acknowledgements}

The author wishes to express his sincere gratitude to Department of Anatomy, Institute of Medical Sciences, Banaras Hindu University.

\section{Conflict of interest}

Author declares that there is no conflict of interest.

\section{References}

1. Finnell RH. Teratology: general considerations and principles. J Allerg Clin Immunol. 1999;103(2):S337-S342.

2. Giavini E, Menegola E. Gene-teratogen chemically induced interactions in congenital malformations. J Biol Neonate. 2004;85(2):73-81.

3. De santis M, Straface J, Carducci B, et al. Risk of drug-induced congenital defects. Eur J Obestet Gynecol Reprod Biol. 2004;117(1):9-10.

4. Hood E. Nanotechnology: looking as we leap. Environ Health Perspect. 2004;112(13):A741-A779.

5. Fu J, Ji J, Fan D, et al. Construction of antibacterial multilayer films containing nanosilver via layer-by-layer assembly of heparin and chitosan-silver ions complex. J Biomed Mater Res. 2006;79(3):665-674.

6. Alt V, Bechert T, Steinrücke P, et al. An in vitro assessment of the antibacterial properties and cytotoxicity of nanoparticulate silver bone cement. J Biomaterials. 2004;25(18):4383-4391.

7. Melaiye A, Sun Z, Hindi K, et al. Silver (I)-imidazole cyclophane gemdiol complexes encapsulated by electro spun tecophilic nanofibers: formation of nanosilver particles and antimicrobial activity. $J$ Am Chem Soc. 2005;127(7):2285-2291.

8. Hussain M, Hess KL, Gearhart JM, et al. In vitro toxicity of nanoparticles in BRL 3A rat liver cells. J Toxicol In-Vitro. 2005;19(7):975-983.

9. Soto K, Garza LE, Murr LE. Cytotoxic effects of aggregated nanomaterials. Acta Biomater. 2007;3(3):351-358.

10. Bar Ilan O, Albrecht RM, Fako VE, et al. Toxicity assessments of multi-sized gold and silver nanoparticles in zebra fish embryos. Small. 2009;5(16):1895-1910.

11. Yamazaki T, Yamayaki A, Hibino Y, et al. Biological impact of contact with metals on cells. In-vivo. 2006;20(5):605-611.

12. Braydich Stolle L, Hussain S, Schlager J, et al. In vitro cytotoxicity of nanoparticles in mammalian germ line stem cells. Toxicol Sci. 2005;88(2):412-419.

13. Dawson AB. A note on the staining of the skeleton of cleared specimen with Alizarin Red-S. Stain Technology. 1926;1(4):123-124.
14. Benn T, Cavanagh B, Hristovski K, et al. The release of nanosilver from consumer products used in the home. $J$ Environ Qual. 2010;39(6):1875-1882.

15. Sawosz E, Grodzik M, Zielinska M, et al. Nanoparticles of silver do not affect growth, development and DNA oxidative damage in chicken embryos. J Arch Geflugelk. 2009;73(3):208-213.

16. Stebounova LV, Adamcakova Dodd A, Kim JS, Nanosilver induces minimal lung toxicity or inflammation in a sub acute murine inhalation model part fibre. Part Fibre Toxicol. 2011;8(1):5.

17. Kim YS, Song MY, Park JD. Sub chronic oral toxicity of silver nanoparticles. Part Fibre Toxicol. 2010;6(7):20.

18. McCauley RL, Li Y, Chopra V, et al. Cytoprotection of human dermal fibroblasts against silver sulfadiazine using recombinant growth factors. J Surg Res. 1994;56(4):378-384.

19. Blumberg H, Carey TN. Argyremia detection of unsuspected and obscure argyria by the spectrographic demonstration of high blood silver. J Am Med Assoc. 1934;103(20):1521-1524.

20. Rosenman KD, Moss A, Kon S. Argyria: Clinical implications of exposure to silver nitrate and silver oxide. J Occup Med. 1979;21(6):430435.

21. Moss AP, Sugar A, Hargett NA. The ocular manifestations and functional effects of occupational argyrosis. $J$ Arch Opthhalmol. 1979;97(5):906-908.

22. Williams N. Longitudinal medical surveillance showing lack of progression of argyrosis in a silver refiner. Occup Med. 1999;49(6):397-399.

23. Chang ALS, Khosravi V, Egbert B. A case of argyria after colloidal silver ingestion. J Cutan Pathol. 2006;33(12):809-811.

24. Tang J, Xi T. Status of biological evaluation on silver nanoparticles. $J$ Sheng Wu Yi Xue Gong Cheng Xue Za Zhi. 2008;25(4):958-961.

25. Stepien KM, Morris R, Brown S, et al. Unintentional silver intoxication following self-medication: an unusual case of corticobasal degeneration. Ann Clin Biochem. 2009;46(Pt 6):520-522.

26. Korani M, Rezayat SM, Gilani K, et al. Acute and sub chronic dermal toxicity of nanosilver in guinea pig. Int J Nanomed. 2011;6:855-862.

27. Chernoff GF. The fetal alcohol syndrome in mice: an animal model. Teratology. 1977;15(3):223-230.

28. Stuckey E, Berry CL. The effect of high dose sporadic (binge) alcohol intake in mice. J Pathol. 1984;142(3):175-180.

29. Webster WS, Walsh DA, McEvan SE, et al. Some teratogenic properties of ethanol and acetaldehyde in C57BL/6 J mice: Implication for the study of the fetal alcohol syndrome. Teratology. 1983;27(2):231-243.

30. Rasmussen B, Brain Christensen N. Teratogenic effect of maternal alcohol consumption on the mouse fetus. A histopathological study. Acta Pathol Microbiol Scand A. 1980;88(5):285-289.

31. Clarren SK, Alvord EC, Sumi SM. Brain malformation related to prenatal exposure of ethanol. J Pediatr. 1978;92(1):64-67. 